\title{
PENGELOMPOKKAN PADA KENDARAAN BERMOTOR MENURUT KEGUNAANNYA MENGGUNAKAN METODE DATA MINING K-MEANS
}

\author{
Windayani Pulungan ${ }^{1}$, Poningsih $^{2}$, Heru Satria $^{3}$
}

${ }^{1}$ Mahasiswa STIKOM Tunas Bangsa, Pematangsiantar, Indonesia

${ }^{2,3}$ Dosen STIKOM Tunas Bangsa, Pematangsiantar, Indonesia

Email: ${ }^{1}$ windayanipulungan605@gmail.com, ${ }^{2}$ poningsih@amiktunasbangsa.ac.id,, ${ }^{3}$ heru@ amiktunasbangsa.ac.id

\begin{abstract}
Abstrak
Penelitian ini bertujuan untuk mencari pengelompokkan data yang ada pada kendaraan bermotor menurut kegunaannya. Jenis-jenis kendaraan bermotor dalam penelitian ini yaitu mulai dari sepeda motor, mobil, angkutan umum, taxi, angkot, bus, dan pick up. Dalam hal ini dibutuhkan suatu metode yang dapat mengelompokan data-data kendaraan bermotor menurut kegunaannya. Penelitian ini dilakukan di Pematangsiantar dan menggunakan metode Data Mining K-Means. Metode K-Means berusaha mengelompokkan data yang ada kedalam beberapa kelompok, dimana data dalam satu kelompok mempunyai karakteristik yang sama satu sama lainnya dan mempunyai karakteristik yang berbeda dengan data yang ada didalam kelompok yang lain. Cluster Tertinggi dengan jumlah data kendaraaan bermotor menurut kegunaannya sebanyak 7 kendaraan yaitu, Roda 3, Taxi, Angkot, Bus (angkutan umum), Truck/Pick Up (angkutan umum), Mobil, Truck/Pick Up (angkutan pribadi).
\end{abstract}

Kata kunci: Data Mining, Metode K-Means, Pengelompokkan Kendaraan Bermotor

\begin{abstract}
This study aims to look for the grouping of data in motor vehicles according to their use. The types of motorized vehicles in this study are ranging from motorbikes, cars, public transportation, taxis, public transportation, buses, and pick ups. In this case we need a method that can classify vehicle data according to its use. This research was conducted in Pematangsiantar and used the KMeans Data Mining method. K-Means method tries to group existing data into several groups, where data in one group has the same characteristics with each other and has different characteristics from the data in other groups. The highest cluster with the number of motorized vehicle data according to its use is 7 vehicles, namely, 3 wheels, Taxi, public transportation, Bus (public transportation), Truck / Pick Up (public transportation), Car, Truck / Pick Up (private transportation).
\end{abstract}

Keywords: Data Mining, K-Means Method, Grouping of Motorized Vehicles.

\section{PENDAHULUAN}

Kendaraan bermotor adalah kendaraan yang digerakkan oleh peralatan teknik untuk penggerakannya, dan digunakan untuk transportasi darat. Kendaraan bermotor memiliki roda dan biasanya berjalan diatas jalanan. Jenisjenis kendaran bermotor dapat bermacam - macam mulai dari mobil, bus, sepeda motor, dan truk. Penelitian ini menggunakan metode data mining $K$-Means untuk mengelompokkan kendaraan bermotor menurut kegunaannya. Penggalian data ditujukan untuk mengelompokkan data kendaraan bermotor menurut kegunaannya di Kota Pematangsiantar.

Banyak masyarakat yang saat ini menggunakan kendaraan bermotor tidak pada fungsi dari kendaraan yang digunakan. Sehingga perlu dilakukannya pengelompokkan kendaraan bermotor menurut kegunaannya, dalam pengelompokkannya diperlukan sebuah model data mining k-means untuk membantu pengelompokkan kendaraan bermotor menurut kegunaannya.

Yang pada pengelompokkan kendaraan, sekumpulan kendaraan yang akan dikelompokkan sesuai dengan karakteristik yang dimiliki setiap kendaraan. Untuk melakukan proses pengelompokkan terdapat sebuah algoritma yang sering digunakan karena sifatnya yang relatif cepat dan mudah beradaptasi yaitu algoritma $K$-Means. $K$-Means merupakan salah satu metode data clustering nonhirarki yang mengelompokkan data dalam bentuk satu atau lebih cluster. Data yang memiliki karakteristik yang sama dikelompokkan dalam satu cluster dan data yang memiliki karakteristik yang berbeda dikelompokkan dengan cluster yang lain, sehingga data yang berada dalam satu cluster memiliki tingkat variasi yang kecil. Salah satu jurnal yan menjadi referensi dalam penulisan skripsi ini berjudul Penerapan Algoritma K-Means Clustering Analysis Pada Penyakit Menular Manusia. Penelitian ini menggunakan teknik data mining dengan algoritma $K$-Means untuk mengelompokkan penyakit menular pada manusia berdasarkan yang frekuensi kejadian. Analisis Cluster penyakit menular pada manusia dilakukan sehingga setiap penyakit yang paling banyak kesamaannya dengan objek lain akan berada dalam cluster yang sama..

\section{METODOLOGI PENELITIAN}

\subsection{Data Mining}

Data Mining merupakan proses maupun kegiatan mengumpulkan sekumpulan data dalam jumlah yang besar untuk di ekstraksi sehingga menjadi informasi yang dapat digunakan[1]. Data mining adalah proses yang menggunakan teknik statistik, matematika, kecerdasan buatan, dan machine learning untuk mengekstraksi dan mengidentifikasi informasi yang bermanfaat dan pengetahuan yang terkait dari database yang besar. Tujuan utama 
data mining adalah untuk menemukan, menggali, atau menambang pengetahuan dari data atau informasi yang kita miliki[2].

\subsection{Cluster}

Menurut Baskoro cluster atau klusterisasi adalah salah satu alat bantu pada data mining yang bertujuan mengelompokkan objek-objek ke dalam cluster - cluster. Cluster adalah metode penganalisaan data, yang sering dimasukkan sebagai salah satu metode Data mining, yang tujuannya adalah untuk mengelompokkan data dengan karakteristik yang sama ke suatu wilayah yang sama dan data dengan karakteristik yang berbeda ke wilayah yang lain[3]. Cluster berbeda dari klasifikasi karena cluster tidak memiliki variabel target. Tujuan cluster bukan untuk mengklasifikasikan, memperkirakan, atau memprediksi nilai variabel taget.

\subsection{K-Means}

K-Means merupakan suatu algoritma yang digunakan dalam pengelompokkan secara pertisi yang memisahkan data ke dalam kelompok yang berbeda-berda. Algoritma ini mampu meminimalkan jarak antara data ke cluster nya [4].

Secara umum algoritma $K$-Means memiliki langkah-langkah dalam pengelompokan [5]:

1. Inisilisasi: menentukan nilai $K$ centroid yang diinginkan dan metrik ketidakmiripan (jarak) yang diinginkan.

2. Memilih $K$ data dari set $X$ sebagai centroid. Untuk menentukan centroid dapat menggunakan persamaan.

\section{Jumlah Data \\ Jumlah Class+1}

3. Mengalokasikan semua data ke centroid terdekat dengan matrik jarak yang telah ditetapkan.

4. Menghitung kembali centroid $C$ berdasarkan data yang mengikuti cluster masing - masing.

5. Mengulangi langkah 3 dan 4 hingga kondisi konvergen tercapai.

Berikut ini adalah rumus untuk menentukan jumlah cluster :

$\mathrm{K}=\sqrt{\frac{N}{2}}$

Keterangan:

$\mathrm{K}=$ klaster

$\mathrm{N}=$ jumlah data

Menghitung jarak pada ruang jarak Euclidean menggunakan formula:

$D\left(x_{2}, x_{1}\right)=\left\|x_{2}-x_{1}\right\|_{2}$

$\sqrt{\sum_{j=1}^{p}\left|x_{2 j}-x_{1 j}\right|^{2}}$

Keterangan:

$D=$ euclidean distance

$x=$ banyaknya objek

$\sum^{P}=$ jumlah data record

\section{HASIL DAN PEMBAHASAN}

\subsection{Analisis Data}

Proses analisa data dapat dilakukan setelah adanya pengumpulan data yang bersifat valid. Dalam melakukan penelitian ini, penulis melakukan analisa data statistik bersifat sekunder yang dimana data diperoleh tidak dari sumbernya langsung, melainkan sudah dikumpulkan dan diolah secara terinci, dimana data berkaitan dengan permasalahan yang sedang diteliti.

\begin{tabular}{ccccc} 
Tabel 1. Data Jumlah Kendaraan Bermotor Menurut Kegunaannya \\
\cline { 3 - 5 } Jenis Kendaraan & \multicolumn{3}{c}{ Jumlah } \\
\cline { 3 - 5 } & & $\mathbf{2 0 1 3}$ & $\mathbf{2 0 1 4}$ & $\mathbf{2 0 1 5}$ \\
\hline Sepeda Motor & Roda 2 & 50.41 & 43.12 & 41.94 \\
Angkutan Umum & Roda 3 & 46 & 63 & 68 \\
& Taxi & - & - & - \\
& Angkot & 1.481 & 1.630 & 1.557 \\
& Bus & 430 & 396 & 387 \\
& Truck/Pick & 1.131 & 1.092 & 1.081 \\
& Up & & &
\end{tabular}




\begin{tabular}{lllll} 
Angkutan Pribadi & Mobil & 1.746 & 1.729 & 1.609 \\
& Bus & 7.048 & 7.100 & 7.263 \\
& Truck/Pick & 3.582 & 3.034 & 2.869 \\
& Up & & & \\
\hline
\end{tabular}

mengelompokkan Kendaraan Bermotor Menurut Kegunaannya menggunakan algoritma K-Means :

1. Menentukan jumlah data yang akan di cluster, dimana sampel data kendaraan bermotor menurut kegunaannya yang akan digunakan dalam proses clustering adalah data kendaraan bermotor menurut kegunaannya terdapat pada Badan Pusat Statistik pada tahun 2013-2015.

Tabel 2. Data Jumlah Kendaraan Bermotor Menurut Kegunaannya setelah melakukan proses rata-rata.

\begin{tabular}{llllll}
\hline \multirow{2}{*}{ Jenis Kendaraan } & & Jumlah & & \\
\cline { 2 - 5 } Sepeda Motor & Roda 2 & 50.413 & 43.121 & 41.945 & 45.160 \\
Angkutan Umum & Roda 3 & 46 & 63 & 68 & 59 \\
& Taxi & - & - & - & 0 \\
& Angkot & 1.481 & 1.630 & 1.557 & 1.556 \\
& Bus & 430 & 396 & 387 & 404 \\
& Truck/Pick & 1.131 & 1.092 & 1.081 & 737 \\
& Up & & & & \\
Angkutan Pribadi & Mobil & 1.746 & 1.729 & 1.609 & 1.228 \\
& Bus & 7.048 & 7.100 & 7.263 & 7.137 \\
& Truck/Pick & 3.582 & 3.034 & 2.869 & 3.162 \\
& Up & & & & \\
\hline
\end{tabular}

2. Menetapkan nilai $\mathrm{k}$ jumlah cluster jumlah kendaraan bermotor menurut kegunaannya sebanyak 3 cluster (k-3). Cluster yang dibentuk yaitu cluster tertinggi, cluster sedang, dan cluster terendah.

3. Menentukan nilai centroid (pusat cluster) awal yang telah ditentukan secara random berdasarkan nilai variabel data yang di cluster sebanyak k yang ditentukan sebelumnya. Adapun cluster tertinggi diperoleh dari nilai tertinggi pada tabel 3, cluster sedang diambil dari nilai rata-rata pada tabel 3.3, dan cluster terendah diambil dari nilai terkecil pada tabel 3. Berikut adalah tabel penentuan centroid awal tiap cluster.

\begin{tabular}{ll}
\multicolumn{2}{c}{ Tabel 3. Centroid Data Awal (Iterasi 1) } \\
\hline CLUSTER & $\mathbf{X}$ \\
\hline MAX & $\mathbf{4 5 , 1 6 0}$ \\
AVERAGE & $\mathbf{7 , 1 3 7}$ \\
MIN & $\mathbf{8 6 2}$ \\
\hline
\end{tabular}

4. Menghitung jarak setiap data kendaraan bermotor menurut kegunaannya terhadap pusat cluster. Setelah data nilai pusat cluster awal ditentukan, maka langkah selanjutnya adalah menghitung jarak masing-masing data terhadap pusat cluster dengan menggunakan rumus yang perhitungannya dapat kita lihat sebagai berikut:

Dilakukan perhitungan jarak terhadap data kendaraan bermotor menurut kegunaannya dengan titik pusat (centroid) pada cluster pertama.

$$
\begin{array}{ll}
\mathrm{D}(1.1) & =\sqrt{45,160-45,160)^{2}}=0 \\
\mathrm{D}(1.2) & =\sqrt{45,160-59)^{2}}=45,101 \\
\mathrm{D}(1.3) & =\sqrt{45,160-0)^{2}}=45,160 \\
\mathrm{D}(1.4) & =\sqrt{45,160-1,556)^{2}}=43,604 \\
\mathrm{D}(1.5) & =\sqrt{45,160-404)^{2}}=44,755 \\
\mathrm{D}(1.6) & =\sqrt{45,160-737)^{2}}=44,422 \\
\mathrm{D}(1.7) & =\sqrt{45,160-1,118)^{2}}=44,041 \\
\mathrm{D}(1.8) & =\sqrt{45,160-7,137)^{2}}=38,023 \\
\mathrm{D}(1.9) & =\sqrt{45,160-2,162)^{2}}=42,998
\end{array}
$$

Perhitungan jarak kendaraan bermotor menurut kegunaannya pertama dengan centroid cluster kedua, seperti berikut :

$\mathrm{D}(2.1) \quad=\sqrt{6,481-45,160)^{2}}=38,678$

$\mathrm{D}(2.2) \quad=\sqrt{6,481-59)^{2}}=6,422$ 
$\mathrm{D}(2.3) \quad=\sqrt{6,481-0)^{2}}=6,481$

$\mathrm{D}(2.4) \quad=\sqrt{6,481-1,556)^{2}}=4,925$

$\mathrm{D}(2.5) \quad=\sqrt{6,481-404)^{2}}=6,077$

$\mathrm{D}(2.6) \quad=\sqrt{6,481-737)^{2}}=5,744$

$\mathrm{D}(2.7) \quad=\sqrt{6,481-1,118)^{2}}=5,363$

$\mathrm{D}(2.8) \quad=\sqrt{6,481-7,137)^{2}}=656$

$\mathrm{D}(2.9) \quad=\sqrt{6,481-2,162)^{2}}=4,320$

Perhitungan jarak kendaraan bermotor menurut kegunaannya pertama dengan centroid cluster ketiga, seperti berikut :
$\mathrm{D}(3.1) \quad=\sqrt{0-45,160)^{2}}=45,160$
$\mathrm{D}(3.2) \quad=\sqrt{0-59)^{2}}=59$
$\mathrm{D}(3.3) \quad=\sqrt{0-0)^{2}}=0$
$\mathrm{D}(3.4) \quad=\sqrt{0-1,556)^{2}}=1,556$
$\mathrm{D}(3.5) \quad=\sqrt{0-404)^{2}}=404$
$\mathrm{D}(3.6) \quad=\sqrt{0-737)^{2}}=737$
$\mathrm{D}(3.7) \quad=\sqrt{0-1,118)^{2}}=1,118$
$\mathrm{D}(3.8) \quad=\sqrt{0-7,137)^{2}}=7,137$
$\mathrm{D}(3.9) \quad=\sqrt{0-2,162)^{2}}=2,162$

Berikut Hasil perhitungan jarak data dengan titik pusat pada iterasi 1 menggunakan Eulidean Distance.

Tabel .4 Hasil perhitungan jarak data dengan titik pusat pada iterasi 1

\begin{tabular}{llllll}
\hline \multicolumn{1}{c}{ Jenis Kendaraan } & \multicolumn{1}{c}{$\mathbf{X}$} & \multicolumn{1}{c}{$\mathbf{C 1}$} & \multicolumn{1}{c}{$\mathbf{C 2}$} & \multicolumn{1}{c}{$\mathbf{C 3}$} & $\begin{array}{c}\text { iterasi 1 } \\
\text { Jarak Terpenddek }\end{array}$ \\
\hline Roda 2 & 4,5160 & 0 & 38,678 & 4,5160 & 4,5160 \\
Roda 3 & 59 & 45,101 & 6,422 & 59 & 59 \\
Taxi & 0 & 45,160 & 6,481 & 0 & 0 \\
Angkot & 1,556 & 43,604 & 4,925 & 1,556 & 1,556 \\
Bus (angkutan umum) & 404 & 44,755 & 6,077 & 404 & 404 \\
Truck/Pick Up (angkutan umum) & 737 & 44,422 & 5,744 & 737 & 737 \\
Mobil & 1,118 & 44,041 & 5,363 & 1,118 & 1,118 \\
Bus (angkutan pribadi) & 7,137 & 38,023 & 656 & 7,137 & 7,137 \\
Truck/Pick Up (angkutan pribadi) & 2,162 & 42,998 & 4,320 & 2,162 & 2,162 \\
\hline
\end{tabular}

5. Menentukan posisi cluster masing-masing data kendaraan bermotor menurut kegunaannya berdasarkan jarak minimum data terhadap pusat cluster. Data yang memiliki jarak terkecil dengan centroid akan menjadi anggota pada kelompok tersebut. Berikut ini merupakan tabel 5 posisi data dengan tiap cluster pada iterasi ke-1 dengan menggunakan bantuan tanda (1) yang mengatakan data menjadi anggota pada cluster.

Tabel 5. Posisi data hasil pengelompokkan tiap cluster pada iterasi ke-1

\begin{tabular}{lccc} 
Jenis kendaraan & C1 & C2 & C3 \\
\hline Roda 2 & 1 & & \\
Roda 3 & & & 1 \\
Taxi & & 1 \\
Angkot & & & 1 \\
$\begin{array}{l}\text { Bus (angkutan } \\
\text { umum) }\end{array}$ & & & 1 \\
$\begin{array}{l}\text { Truck/Pick Up } \\
\text { (angkutan }\end{array}$ & & 1 \\
umum) & & & \\
Mobil & & & 1 \\
$\begin{array}{l}\text { Bus (angkutan } \\
\text { pribadi) }\end{array}$ & & 1 & \\
$\begin{array}{l}\text { Truck/Pick Up } \\
\text { (angkutan }\end{array}$ & & & \\
pribadi) & & & 1 \\
Jumlah & $\mathbf{1}$ & $\mathbf{1}$ & $\mathbf{7}$ \\
\hline
\end{tabular}


6. Menghitung titik pusat baru menggunakan hasil dari setiap anggota pada masing-masing cluster.

Contoh perhitungan titik pusat baru pada cluster $\mathrm{x}$ adalah:

$$
\begin{aligned}
& \mathbf{C}_{1} \mathrm{X}=\frac{45.160}{1}=45.160 \\
& \mathbf{C}_{2} \mathrm{X}=\frac{7.137}{1}=7.137 \\
& \mathbf{C}_{3} \mathrm{X}=\frac{59+0+1.556+404+737+1.118+2.162}{7}=862
\end{aligned}
$$

\begin{tabular}{ll}
$\begin{array}{l}\text { Berikut tabel 6. Hasil perhitungan cluster baru pada iterasi } \\
\text { CLUSTER }\end{array}$ & $\mathbf{X}$ \\
\hline $\mathbf{C}_{1}$ & $\mathbf{4 5 , 1 6 0}$ \\
$\mathbf{C}_{2}$ & $\mathbf{7 , 1 3 7}$ \\
$\mathbf{C}_{3}$ & $\mathbf{8 6 2}$
\end{tabular}

7. Selanjutnya dilakukan kembali langkah 4 sampai 6. Jika nilai centroid hasil iterasi dengan nilai centroid sebelumnya bernilai sama atau nilai centroid sudah optimal serta posisi cluster data kendaraan bermotor menurut kegunaannya tidak mengalami perubahan lagi maka proses iterasi berhenti. Namun jika nilai centroid tidak sama atau belum optimal serta posisi data kendaraan bermotor menurut kegunaannya masih berubah maka proses iterasi berlanjut pada iterasi berikutnya.

\section{Lanjut iterasi 2}

Tabel 7. pusat cluster iterasi 2

\begin{tabular}{ll}
\hline CLUSTER & $\mathrm{x}$ \\
\hline $\mathrm{C}_{1}$ & $\mathbf{4 5 , 1 6 0}$ \\
$\mathrm{C}_{2}$ & $\mathbf{7 , 1 3 7}$ \\
$\mathrm{C}_{3}$ & $\mathbf{8 6 2}$ \\
\hline
\end{tabular}

Setelah data nilai pusat cluster iterasi 1 didapat maka langkah selanjutnya adalah melakukan perhitungan jarak terhadap data kendaraan bermotor menurut kegunaannya dengan titik pusat (centroid) pada cluster pertama.

$$
\begin{array}{ll}
\mathrm{D}(1.1) & =\sqrt{45,160-45,160)^{2}}=0 \\
\mathrm{D}(1.2) & =\sqrt{45,160-59)^{2}}=45,101 \\
\mathrm{D}(1.3) & =\sqrt{45,160-0)^{2}}=45,160 \\
\mathrm{D}(1.4) & =\sqrt{45,160-1,556)^{2}}=43,604 \\
\mathrm{D}(1.5) & =\sqrt{45,160-404)^{2}}=44,755 \\
\mathrm{D}(1.6) & =\sqrt{45,160-737)^{2}}=44,422 \\
\mathrm{D}(1.7) & =\sqrt{45,160-1,118)^{2}}=44,041 \\
\mathrm{D}(1.8) & =\sqrt{45,160-7,137)^{2}}=38,023 \\
\mathrm{D}(1.9) & =\sqrt{45,160-2,162)^{2}}=42,998
\end{array}
$$

Perhitungan jarak kendaraan bermotor menurut kegunaannya pertama dengan centroid cluster kedua, seperti berikut :

$$
\begin{array}{ll}
\mathrm{D}(2.1) & =\sqrt{7,137-45,160)^{2}}=38,023 \\
\mathrm{D}(2.2) & =\sqrt{7,137-59)^{2}}=7,078 \\
\mathrm{D}(2.3) & =\sqrt{7,137-0)^{2}}=7,137 \\
\mathrm{D}(2.4) & =\sqrt{7,137-1.556)^{2}}=5,581 \\
\mathrm{D}(2.5) & =\sqrt{7,137-404)^{2}}=6,733 \\
\mathrm{D}(2.6) & =\sqrt{7,137-737)^{2}}=6,400 \\
\mathrm{D}(2.7) & =\sqrt{7,137-1.118)^{2}}=6,019 \\
\mathrm{D}(2.8) & =\sqrt{7,137-7.137)^{2}}=0 \\
\mathrm{D}(2.9) & =\sqrt{7,137-2.162})^{2}=4,975
\end{array}
$$

Perhitungan jarak kendaraan bermotor menurut kegunaannya pertama dengan centroid cluster ketiga, seperti berikut :

$\mathrm{D}(3.1) \quad=\sqrt{862-45,160)^{2}}=44.297$

$\mathrm{D}(3.2) \quad=\sqrt{862-59)^{2}}=803$

$\mathrm{D}(3.3) \quad=\sqrt{862-0)^{2}}=862$ 


$\begin{array}{ll}\mathrm{D}(3.4) & =\sqrt{862-1,556})^{2}=694 \\ \mathrm{D}(3.5) & =\sqrt{862-404)^{2}}=458 \\ \mathrm{D}(3.6) & =\sqrt{862-737)^{2}}=125 \\ \mathrm{D}(3.7) & =\sqrt{862-1,118)^{2}}=256 \\ \mathrm{D}(3.8) & =\sqrt{862-7,137)^{2}}=6,275 \\ \mathrm{D}(3.9) & =\sqrt{862-2,162)^{2}}=1,299\end{array}$

Berikut hasil iterasi 2 menggunakan Eulidean Distance.

Tabel 8 Hasil perhitungan jarak data dengan titik pusat pada

\begin{tabular}{llllll}
\hline Jenis Kendaraan & $\mathbf{X}$ & $\mathbf{C 1}$ & $\mathbf{C 2}$ & $\mathbf{C 3}$ & $\begin{array}{l}\text { iterasi 2 } \\
\text { Jarak Terpendek }\end{array}$ \\
\hline Roda 2 & 4,5160 & 0 & 38,023 & 44,297 & 0 \\
Roda 3 & 59 & 45,101 & 7,078 & 803 & 803 \\
Taxi & 0 & 45,160 & 7,137 & 862 & 862 \\
Angkot & 1,556 & 43,604 & 5,581 & 694 & 694 \\
Bus (angkutan umum) & 404 & 44,755 & 6.733 & 458 & 458 \\
Truck/Pick Up (angkutan umum) & 737 & 44,422 & 6,400 & 125 & 125 \\
Mobil & 1,118 & 44,041 & 6,019 & 256 & 256 \\
Bus (angkutan pribadi) & 7,137 & 38,023 & 0 & 6,275 & 0 \\
Truck/Pick Up (angkutan pribadi) & 2,162 & 42,998 & 4,975 & 1,299 & 1,299 \\
\hline
\end{tabular}

Data yang memiliki jarak terkecil dengan centroid akan menjadi anggota pada kelompok tersebut. Berikut ini merupakan tabel 9 posisi data dengan tiap cluster pada iterasi ke-2 dengan menggunakan bantuan tanda (1) yang mengatakan data menjadi anggota pada cluster.

Tabel 9. Posisi data dengan tiap cluster pada iterasi ke-2

\begin{tabular}{llll}
\multicolumn{1}{c}{ Jenis kendaraan } & C1 & C2 & C3 \\
\hline Roda 2 & 1 & & \\
Roda 3 & & & 1 \\
Taxi & & & 1 \\
Angkot & & & 1 \\
Bus (angkutan umum) & & 1 \\
Truck/Pick Up (angkutan umum) & & & 1 \\
Mobil & & 1 \\
Bus (angkutan pribadi) & 1 & \\
Truck/pick up (angkutan pribadi) & & & 1 \\
Jumlah & $\mathbf{1}$ & $\mathbf{1}$ & $\mathbf{7}$ \\
\hline
\end{tabular}

Menghitung titik pusat baru menggunakan hasil dari setiap anggota pada masing-masing cluster Contoh perhitungan titik pusat baru pada cluster $\mathrm{x}$ :

$\mathbf{C}_{1 \times}=\frac{45.160}{1}=45.160$

$\mathbf{C}_{2} \mathrm{X}=\frac{7.137}{1}=7.137$

$\mathbf{C}_{3 \mathrm{X}}=\frac{59+0+1.556+404+737+1.118+2.162}{7}=862$

Berikut tabel 10. Hasil perhitungan cluster baru pada iterasi 2

\begin{tabular}{ll} 
Tabel 4.10 Hasil perhitungan cluster baru pada iterasi 2 \\
\hline CLUSTER & $\mathbf{x}$ \\
\hline $\mathbf{C}_{\mathbf{1}}$ & $\mathbf{4 5 , 1 6 0}$ \\
$\mathbf{C}_{\mathbf{2}}$ & $\mathbf{7 , 1 3 7}$ \\
$\mathbf{C}_{\mathbf{3}}$ & $\mathbf{8 6 2}$ \\
\hline
\end{tabular}

\subsection{Tampilan RapidMiner}

Pada penelitian yang didukung dari hasil pemrosesan dengan menggunakan Software Rapidminer yang dimana hasil akhir akurasi penerapan algoritma K-Means Clustering diperoleh Cluster Model cluster 0: 1 item, cluster 1: 7 
item dan cluster 2: 1 item yang dimana jumlah total keseluruhan adalah 9. Untuk melihat nilai akurasi dapat dilihat pada gambar 1.. dibawah ini :

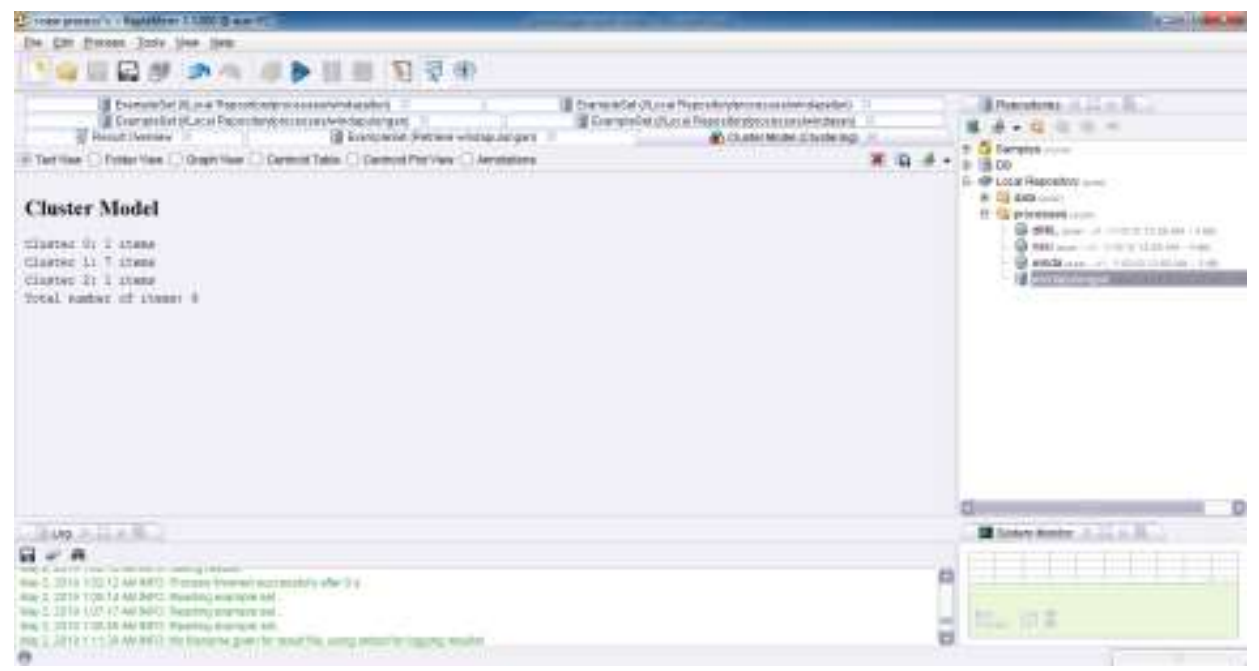

Gambar 1. Data Hasil menggunakan K-Means Clustering

\section{KESIMPULAN}

Adapun kesimpulan dalam penelitian ini adalah :

1. Cluster Tertinggi dengan jumlah data kendaraaan bermotor menurut kegunaannya sebanyak 7 kendaraan yaitu, Roda 3, Taxi, Angkot, Bus (angkutan umum), Truck/Pick Up (angkutan umum), Mobil, Truck/Pick Up (angkutan pribadi).

2. Cluster Sedang dengan jumlah data kendaraan bermotor menurut kegunaannya sebanyak 1 kendaraan yaitu Bus (angkuta pribadi)

3. Cluster Terendah dengan jumlah data kendaraaan bermotor menurut kegunaannya sebanyak 1 kendaraan yaitu, Truck/Pick Up (angkutan pribadi).

4. Pengujian data yang dilakukan dalam penelitian ini, cluster data pemberhentian pada data terjadi di iterasi 1 dan 2 .

5. Nilai hasil akurasi dari perhitungan manual excel dan aplikasi Rapidminer bernilai sama, tetapi urutan hasil cluster manual dan rapidminer bersifat random tidak berurut.

\section{REFERENCES}

[1] A. Saleh, "Klasifikasi Metode Naive Bayes Dalam Data Mining Untuk Menentukan Konsentrasi Siswa ( Studi Kasus Di Mas Pab 2 Medan )," Konf. Nas. Pengemb. Teknol. Inf. Dan Komun., Pp. 200-208, 2014.

[2] R. Setiawan, "Penerapan Data Mining Menggunakan Algoritma K-Means Clustering Untuk Menentukan Strategi Promosi Mahasiswa Baru ( Studi Kasus : Politeknik Lp3i Jakarta ),”Vol. 3, No. 1, Pp. 76-92, 2016.

[3] Surmayanti, "Penerapan Analysis Clustering Pada Penjualan Komputer Dengan Perancangan Aplikasi Data Mining Menggunakan Algoritma K-Means," Pros. Semin. Ilm. Nas. Teknol. Komput, Vol. 1, Pp. 50-59, 2015.

[4] A. K. Wardhani, "Implementasi Algoritma K-Means Untuk Pengelompokkan Penyakit Pasien Pada Puskesmas Kajen Pekalongan," Vol. 14, Pp. 30-37, 2016.

[5] I. Et Al. Parlina, "Memanfaatkan Algoritma K-Means Dalam Menentukan Pegawai Yang Layak Mengikuti Asessment Center Untuk Clustering Program Sdp.," Cess (Journal Comput. Eng. Syst. Sci., Pp. 87-93, 2018. 